\title{
CRÓNICA DE UN DESENCUENTRO: LAS PROVINCIAS DE VENEZUELA Y LAS CORTES DE CÁDIZ (1810-1812)
}

ALLAN R. BREWER-CARÍAS 
SUMARIO

1. UN PUNTO DE CONVERGENCIA EN EL ORIGEN DEL DESENCUENTRO: LA CRISIS DEL ANTIGUO RÉGIMEN ESPAÑOL. 2. LAS RUTAS DEMOCRÁTICO REPRESENTATIVAS QUE CONDUJERON AL DESENCUENTRO. 3. LA CONSOLIDACIÓN DEL DESENCUENTRO: LA GUERRA DECRETADA POR LA REGENCIA Y CONTINUADA POR LAS CORTES DE CÁDIZ, CONTRA LAS PROVINCIAS DE VENEZUELA. 4. LA CONVERGENCIA CONSTITUCIONAL ENTRE CARACAS (1811) Y CÁDIZ (1812), A PESAR DEL DESENCUENTRO, POR LA RECEPCIÓN DE LOS MISMOS PRINCIPIOS DEL CONSTITUCIONALISMO MODERNO. 5. ALGUNAS SECUELAS CONSTITUCIONALES DEL DESENCUENTRO. 


\title{
CRÓNICA DE UN DESENCUENTRO: LAS PROVINCIAS DE VENEZUELA Y LAS CORTES DE CÁDIZ (1810-1812)*
}

\author{
ALLAN R. BREWER-CARÍAS \\ Profesor de la Universidad Central de Venezuela \\ Adjunct Professor of Law, Columbia Law School (2006-2007)
}

Entre las Provincias coloniales del Imperio español que conformaban la Capitanía General de Venezuela en la parte septentrional de América del Sur, y las autoridades que funcionaban en la Metrópolis, luego del secuestro de Carlos IV y Fernando VII en 1808 por parte del Emperador de los franceses, Napoleón Bonaparte, y la invasión por sus tropas de la Península ibérica; puede decirse que se comenzó a gestar lo que sería un gran desencuentro entre las nuevas autoridades que en paralelo se conformaron en ambas partes del Atlántico.

Ello, además, se reflejó en los procesos constituyentes que se desarrollaron a partir de 1810 en Venezuela y en España. El tiempo hizo que en ambas partes coincidieran, por un lado, el inicio del proceso de independencia de las Provincias Americanas respecto del Imperio Español, lo que condujo a la lucha de las autoridades españolas contra las nuevas autoridades constituidas en América que proclamaban su independencia; y por el otro, la lucha que las precarias autoridades de la Península, sin Rey presente e invadida por los franceses, también llevaban a cabo para lograr su propia independencia del Imperio francés. Esos dos hechos produjeron al desarrollo de sendos procesos constituyentes, que en Amé-

* Texto preparado para el Congreso sobre La Constitución de 1812. La participación de los Diputados de América, organizado por la Universidad Interamericana, Puerto Rico y el Consulado General de España en Puerto Rico, San Juan, 19 al 21 de octubre de 2011. 
rica desembocó en el establecimiento de nuevos Estados republicanos independientes, y en España, en el establecimiento de una Monarquía constitucional, aún cuando en ambos casos con vicisitudes y rupturas; habiendo reflejado sido el resultado del proceso constituyente, en ambos casos, la sanción de Constituciones en el sentido del constitucionalismo moderno ${ }^{1}$.

Ello produjo, al contrario de lo que sucedió en el resto de la América Hispana, que en el proceso constituyente inicial desarrollado en las antiguas Provincias de Venezuela se hubiese sancionado la Constitución Federal para los Estados de Venezuela de 21 de diciembre de 1811, así como de otras diversas Constituciones provinciales en dichas Provincias de Venezuela y en las de la Nueva Granada entre 1810-1812; y que en el proceso constituyente de Cádiz se hubiese sancionado la Constitución de la Monarquía Española de 19 de marzo de 1812, sin influencia alguna en la primera.

Estas notas están destinadas a ilustrar, brevemente, la crónica de ese desencuentro.

\section{UN PUNTO DE CONVERGENCIA EN EL ORIGEN DEL DESENCUENTRO: LA CRISIS DEL ANTIGUO RÉGIMEN ESPAÑOL}

En 1808 y en 1810, tanto en España como en Caracas se produjo una ruptura del orden político gubernativo existente, lo que se materializó en el hecho político de que el poder de gobernar tanto el Reino de España como las provincias de la América meridional, lo asumieron órganos que se formaron ex novo para tales efectos, y que no estaban previstos en el ordenamiento constitucional del Antiguo Régimen ni del régimen colonial. Técnicamente, en esos años y en ambos confines de la península y americanos, se produjo un golpe de Estado, que sería el inicio de sendos procesos constituyentes.

En 25 de septiembre de 1808, en efecto, luego de los sucesos de Aranjuez y de las abdicaciones de Bayona, en Aranjuez se instaló una Junta Suprema Central y Gubernativa del Reino, también llamada Junta Suprema o Junta Central Suprema, que fue el órgano que asumió el poder del Estado en ausencia del Rey Fernando VII y durante la ocupación por los ejércitos napoleónicos de España lo que se había iniciado desde marzo de 1808. Su constitución se produjo tras la victoria lograda por los ejércitos españoles en la batalla de Bailén en 19 de julio de 1808 , en lo que sería la primera derrota en la historia que tuvo el ejército napo-

${ }^{1}$ Véase en general Allan R. Brewer-Carías, Los inicios del proceso constituyente Hispano y Americano: Caracas 1811 — Cádiz 1812, Ed. Bid \& co. Editor, Caracas 2011. 
leónico, y después de que el Consejo de Castilla hubiese declarado nulas las abdicaciones a la Corona de España a favor de Napoleón que se habían efectuado en Bayona, en mayo de ese mismo año, tanto de parte del Rey Carlos IV como de su hijo el Rey Fernando VII. Esa Junta Central, formada inicialmente por representantes de las Juntas Provinciales, también constituidas durante la guerra de independencia, ejerció el poder político del reino hasta el 30 de enero de 1810, cuando la Junta Central al disolverse y convocar a la elección de las Cortes, decidió trasladarlo a un Consejo de Regencia.

Ante las noticias de los acontecimientos de Bayona, cuando unos meses después las mismas llegaron a Caracas, el Capitán General de Venezuela formuló una declaración solemne, el 18 de julio de 1808, expresando que en virtud de que «ningún gobierno intruso e ilegítimo puede aniquilar la potestad legítima y verdadera» por los hechos acaecidos en la Península «en nada se altera la forma de gobierno ni el Reinado del Señor Don Fernando VII en este Distrito» ${ }^{2}$. A ello se sumó, el 27 de julio, el Ayuntamiento de Caracas, al expresar que «no reconocen ni reconocerán otra Soberanía que la suya (Fernando VII), y la de los legítimos sucesores de la Casa de Borbón» ${ }^{3}$.

En esa misma fecha, incluso, el Capitán General se dirigió al Ayuntamiento exhortándolo a que se erigiese en esta Ciudad «una Junta a ejemplo de la de Sevilla» ${ }^{4}$, para cuyo efecto, el Ayuntamiento tomó conocimiento del acto del establecimiento de aquélla ${ }^{5}$ y acordó estudiar un «Prospecto» cuya redacción encomendó a dos de sus miembros, el cual llegó a ser aprobado el 29 de julio de 1808, pasándolo para su aprobación al «Presidente, Gobernador y Capitán General» ${ }^{6}$. Este, sin embargo, nunca llegó a considerar la propuesta, a pesar de la representación que el 22 de noviembre de 1808 le habían enviado las primeras no-

${ }^{2}$ Véase en José Félix Blanco y Ramón Azpúrua, Documentos para la Historia de la Vida Pública del Libertador de Colombia, Perú y Bolivia. Puestos por orden cronológico y con adiciones y notas que la ilustran, La Opinión Nacional, Vol. III, Caracas 1877, Edición facsimilar: Ediciones de la Presidencia de la República, Caracas 1977, 1983, Tomo II, p. 169.

3 Idem., p. 169.

${ }^{4}$ Idem., pp. 170-174. Caracciolo Parra Pérez, Historia de la Primera República de Venezuela, Biblioteca de la Academia Nacional de la Historia, Caracas, 1959, Tomo I. pp. 311 y ss., y 318.

5 Véase el acta del Ayuntamiento del 28-7-1808 en J.F. Blanco y R. Azpúrua, Documentos para la Historia.... Tomo II, p. 171. Debe señalarse que en la misma línea de acción, Francisco de Miranda en carta enviada al Marqués del Toro el 20 de julio de 1808 expresaba la necesidad de que en Caracas, «reuniéndose en un cuerpo municipal representativo, tomen a su cargo el gobierno de esa provincia.» Véase Giovanni Meza Dorta, Miranda y Bolívar, bid\&co. Editor, Caracas 2007 p. 43.

${ }^{6}$ Véase el texto del prospecto y su aprobación de 29-7-1809, en .F. Blanco y R. Azpúrua, Documentos para la Historia.., Tomo II, pp. 172-174. Véase C. Parra Pérez, Historia de la Primera República...., p. 318. 
tabilidades de Caracas designadas para tratar con él sobre «la formación y organización de la Junta Suprema.»

En todo caso, y siempre en medio de la incertidumbre acrecentada por la distancia, el 12 de enero de 1809, el Ayuntamiento de Caracas reconoció en Venezuela a la Junta Central, como el gobierno supremo del Imperio ${ }^{7}$.

Días después, fue que la Junta Suprema Central de España por Real Orden de 22 de enero de 1809, dispondría que:

Los vastos y preciosos dominios que la España posee en las Indias no son propiamente colonias o factorías, como los de otras naciones, sino una parte esencial e integrante de la monarquía española ${ }^{8}$.

Posteriormente, el 19 de abril de 1810, ante la noticia recibida el día anterior en el Ayuntamiento de Caracas sobre la material desaparición del Gobierno Supremo en España y el confinamiento en la ciudad de Cádiz, del para ese momento recién constitutito Consejo de Regencia por la disolución de la Junta Central, por la invasión napoleónica; en Caracas se consideró necesario constituir un gobierno que se hiciese cargo de las Provincias de Venezuela para asegurarlas contra los designios del Emperador francés. Fue así que el propio Cabildo de Caracas, contra la voluntad del Gobernador, al fin se erigió en Junta Suprema de Venezuela Conservadora de los Derechos de Fernando VII, la cual, asumiendo el «mando supremo» o «suprema autoridad» de la Provincia, procedió a constituir «un nuevo gobierno», deponiendo al Gobernador y Capitán General del mando. La motivación inmediata de este hecho político había sido la «total orfandad» en la cual se consideró había quedado el pueblo después de la abdicación de los reyes y luego por la disolución de la Junta Suprema Gubernativa de España, que suplía la ausencia del Monarca, ya que la Junta Suprema que se había establecido en Caracas había desconocido la autoridad misma del Consejo de Regencia, considerando que el mismo no había «sido constituido por el voto de estos fieles habitantes, cuando han sido ya declarados, no colonos, sino partes integrantes de la corona de España, y, como tales han sido llamados al ejercicio de la soberanía interna y a la reforma de la Constitución Nacional» ${ }^{9}$. Ello lo reiteraría la Junta Suprema el

7 Idem., Tomo II, p. 305.

${ }^{8}$ Véase el texto en J.F. Blanco y R. Azpúrua, Documentos para la Historia...., Tomo II, pp. 230-231. Véase O. C. Stoetzer, Las Raíces Escolásticas de la Emancipación de la América Española, Madrid, 1982., p. 271. En esa disposición se encargaba a los Ayuntamientos a designar representantes ante la Junta central, y en Venezuela, el Ayuntamiento designó a Joaquín Mosquera y Figueroa, regente de la Audiencia de caracas; nombramiento que luego fue anulado por no ser nativo de la provincia e incompatibilidad de cargos. Véase Juan Garrido Rovira, La Revolución de 1810, Universidad Monteávila, Caracas 2009, p.79.

9 Véase el texto del Acta del 19-04-1810 en Allan R. Brewer-Carías, Las Constituciones de Venezuela, Academia de Ciencias Políticas y Sociales, Caracas 2008, Tomo I, pp. 531-533. 
el 5 de mayo de 1810 al dirigirse a la Regencia cuestionándole su autoridad y representatividad, así como la de los eventuales diputados que pudieran elegirse para las Cortes por los cabildos americanos, señalándole «en una palabra, desconocemos el nuevo Consejo de Regencia» ${ }^{10}$.

Con esos hechos, por tanto, en 1808 y 1810, tanto en España como en Hispanoamérica, se dio inicio a sendos procesos constituyentes que como se dijo, desembocaron en la sanción en Caracas, de la «Constitución Federal para los Estados de Venezuela» en 21 de diciembre de 1811, y unos meses después, el 19 de marzo de 1812 en la sanción en Cádiz, de la «Constitución de la Monarquía Española»; ambas producto de lo que puede denominarse como la Revolución Hispano-Americana, iniciada veintidós años después de la Revolución Francesa y treinta y cinco años después de la Revolución Norteamericana. Junto con estas, esa Revolución pasó a formar parte de los procesos políticos más importantes del mundo moderno en materia constitucional, con los cuales se inició la transformación radical del orden político constitucional que hasta entonces era el imperante en el Antiguo Régimen español y en las Colonias españolas de América.

Puede decirse entonces que Venezuela y España, a comienzos del Siglo XIX, fueron los primeros países en el mundo que recibieron directamente las influencias del constitucionalismo moderno derivadas de las mencionadas Revoluciones del Siglo XVIII ${ }^{11}$, lo que ocurrió en forma paralela, precisamente cuando los próceres del proceso de Independencia de Venezuela, después del 19 de abril de 1810 se encontraban en la tarea de elaborar las bases del sistema jurídico-estatal que habría de regir un nuevo Estado independiente, que era el segundo en su género en la historia política del mundo moderno después de los Estados Unidos de Norte América; y cuando los constituyentes de Cádiz, después del proceso de recomposición del régimen monárquico que se había iniciado con los sucesos de Aranjuez y Bayona en 1808 , llevaban a cabo la tarea de transformar una Monarquía absoluta en una Monarquía constitucional, lo que antes había ocurrido precisamente en Francia, como consecuencia de la Revolución. Por ello fue que la Constitución de

10 Véase Textos Oficiales de la primera República de Venezuela, Biblioteca de la Academia de Ciencias Políticas y Sociales, Caracas 1982, Tomo I, p. 134.

${ }^{11}$ Véase en general Allan R. Brewer-Carías, Reflexiones sobre la Revolución Americana (1776) y la Revolución Francesa (1789) y sus aportes al constitucionalismo moderno, Caracas, 1991. Una segunda edición ampliada de este libro se publicó como Reflexiones sobre la Revolución Norteamericana (1776), la Revolución Francesa (1789) y la Revolución Hispanoamericana (1810-1830) y sus aportes al Constitucionalismo Moderno, Serie Derecho Administrativo No. 2, Universidad Externado de Colombia, Editorial Jurídica Venezolana, Bogotá 2008. 
Cádiz de 1812, no tuvo influencia en el proceso constituyente venezolano y neogranadino; lo que ciertamente, fue un hecho único en la América Hispana, pues al contrario, en la mayoría de las otras antiguas Colonias americanas españolas que lograron su independencia particularmente después de 1820, las mismas recibieron las influencias del naciente constitucionalismo español plasmado en la Constitución de Cádiz de 1812, con motivo de su puesta en vigencia, de nuevo en $1820^{12}$.

Esos procesos constituyentes que originaron la sanción de las Constituciones de Venezuela y de Cádiz, en todo caso, estuvieron a cargo de Asambleas Constituyentes que se concibieron y constituyeron al efecto, como instituciones representativas de la soberanía nacional, la cual ya se consideraba había sido trasladada al pueblo, integradas por diputados electos en elecciones indirectas en las diversas demarcaciones territoriales de las provincias tanto del reino de España como de la antigua Capitanía General de Venezuela. Esas fueron, por un lado, las Cortes de Cádiz en España, y por la otra, la Junta o Congreso General de Diputación de las Provincias en Venezuela.

Con ello, en ambos casos, se buscó salir de la crisis política en la cual se encontraban los países: en España, como hemos dicho, provocada, desde 1808, por el secuestro del Rey y la invasión de la Península Ibérica por las tropas de Napoleón, lo cual en medio de la dura guerra de independencia desarrollada por las diversas provincias, había originado la constitución de Juntas Supremas conservadoras de los derechos de Fernando VII en las Provincias más importantes, que luego formarían, entre ellas, la Junta Central de Gobierno para atender los asuntos del Reino. Fue esa Suprema Junta Central de España, precisamente, la que el 30 de enero de 1810 pondría término a su función, delegándola en un Consejo de Regencia nombrado por la misma, no sin antes disponer la convocatoria a Cortes para recomponer el Estado, estableciendo la forma de elección de los diputados.

En Caracas, como también se dijo, la crisis fue provocada igualmente desde 1808, por el sentimiento sostenido de orfandad política que acusaban las Provincias debido al secuestro del Monarca español en manos de un invasor extranjero que no era querido, y la constitución en 1810 de una Junta Suprema que había sustituido al cabildo de Caracas, convocando a su vez a elecciones de una Junta o

12 Véase por ejemplo, Jorge Mario García Laguardia, Carlos Meléndez Chaverri, Marina Volio, La Constitución de Cádiz y su influencia en América (175 años 1812-1987), San José, 1987; Manuel Ferrer Muñoz, La Constitución de Cádiz y su aplicación en la Nueva España, UNAM México, 1993; Ernesto de la Torre Villas y Jorge Mario García Laguardia, Desarrollo histórico del constitucionalismo hispanoamericano, UNAM, México 1976. 
Congreso General de diputados. Por ello, Roscio diría en alguna ocasión que «La abdicación fue el principio de nuestra independencia» ${ }^{13}$.

En ese contexto, ambos procesos constituyentes tenían objetivos precisos: En España, se trataba de la reconstitución política de un Estado preexistente como era el Estado Monárquico, y lograr su transformación en un Estado Monárquico constitucional; y en Venezuela, se trataba de la constitución de un nuevo Estado sobre la que habían sido antiguas Colonias españolas americanas que se habían declarado independientes. En ambos caso, el proceso constituyente tuvo, como común denominador inicial, la adopción del principio de la soberanía popular y la necesidad de reconstituir o constituir los gobiernos de los Estado sobre la base de la representación de sus habitantes, a cuyo efecto, tanto en la Península como en las Provincias de Venezuela, se procedió a dictar en el mismo año 1810 , sendos cuerpos normativos o reglamentos para convocar al pueblo para la elección de los diputados a Cortes, en España, y de los diputados a un Congreso o Junta General, en Venezuela.

\section{LAS RUTAS DEMOCRÁTICO REPRESENTATIVAS QUE CONDUJERON AL DESENCUENTRO}

Se dio inicio así, en cada extremo del Imperio Español, de uno y otro lado del Atlántico, a sendos procesos constituyentes que partieron de similares principios: primero, la ubicación de la soberanía en el pueblo, y segundo, el principio democrático representativo a los efectos de elegir un cuerpo político que redefiniera, o definiera, el régimen político a raíz de la crisis política existente. Para ello, en ambos casos, el primer acto político que se adoptó para culminar esos procesos constituyentes fue la emisión de sendos cuerpos normativos destinados a establecer el sistema y procedimiento para la elección de los diputados, lo que en España hizo la Suprema Junta Gubernativa del Reino el 1 de enero de 1810, y en Venezuela, seis meses más tarde, la Junta Suprema Conservadora de los derechos de Fernando VII, el 11 de junio del mismo año 1810.

Ello condujo, en España, a la convocatoria a Cortes para darle legitimación a la representación nacional, lo que la Junta Central hizo por Decretos de 22 de mayo y 15 de junio de 1809 , fijándose la reunión de las Cortes para el $1^{\circ}$ de marzo de 1810, en la Isla de León ${ }^{14}$. A tal efecto, como se dijo, la Suprema Junta Gu-

${ }^{13}$ En la sesión del Congreso General del 25 de junio de 1811. Véase Libro de Actas del Segundo Congreso de Venezuela 1811-1812, Academia Nacional de la Historia, Caracas 1959, Tomo I, p. 82.

${ }^{14}$ Véase el texto en J.F. Blanco y R. Azpúrua, Documentos para la Historia...., Tomo II, pp. 234-235. 
bernativa dictó, el $1^{\circ}$ de enero de 1810 una Instrucción que deberá observarse para la elección de Diputados a Cortes ${ }^{15}$, en la cual se convocaba a la integración de las Cortes como cuerpo representativo del Reino, a los efectos de que fuera el órgano que tomase «las resoluciones y medidas para salvar la Patria, para restituir al Trono a nuestro deseado Monarca, y para restablecer y mejorar una Constitución que sea digna de la Nación española». Para ello se estableció un sistema electoral indirecto a ser desarrollado en las Provincias de la Península, sin que se previera nada sobre la posible elección de diputados por las Provincias americanas. Fue posteriormente, en la Instrucción del Consejo de Regencia de España e Indias de 14 de febrero de 1810, cuando se declaró que las mismas habrían dejado de ser Colonias y que «eran parte integrante y esencial de la Monarquía española». Con base en ello, el Consejo de Regencia en la misma fecha 14 de febrero de 1810, dirigió a los «españoles americanos» una «alocución» acompañada de un Real Decreto, disponiendo la concurrencia a las Cortes Extraordinarias, al mismo tiempo que de diputados de la Península, de diputados de los dominios españoles de América y de Asia ${ }^{16}$.

La implementación de ese Real Decreto de la misma Junta Suprema Central, sin embargo, sólo se logró de manera parcial e insuficiente y después de mucho debate, mediante el acuerdo del Consejo de Regencia adoptado sólo 15 días antes de la instalación de las Cortes, el día 8 de septiembre de 1810, en el cual se regularon unas normas para la designación de diputados «suplentes» tanto de las provincias peninsulares ocupadas por los franceses como de las provincias americanas, lo que, en estas últimas, provocó protestas, entre ellas, precisamente de Caracas.

En todo caso, conforme a la Instrucción, y a pesar del complejo proceso electoral que se preveía y de la situación política general del Reino, se eligieron los diputados a las Cortes y se designaron los 30 diputados suplentes americanos, con americanos residentes en Cádiz, así: 7 por el Virreinato de México, 2 por la Capitanía General de Guatemala, 1 por la Isla de Santo Domingo, 1 por la Isla de Cuba, 1 por la Isla de Puerto Rico, 2 por Filipinas, 5 por el Virreinato de Lima, 2 por la Capitanía General de Chile, 3 por el Virreinato de Buenos Aires, 3 por el Virreinato de Santafé, y 2 por la Capitanía General de Caracas ${ }^{17}$.

15 Véase además la «Comunicación que acompañó la Comisión de Cortes a la Instrucción que debía observarse para la elección de Diputados a Cortes al someterla a la aprobación de la Junta Central» de 08-09-1809, en Biblioteca Virtual Miguel de Cervantes, en http://www.cervantesvirtual.com/servlet/SirveObras/34695175432370 530854679/p0000001.htm

${ }^{16}$ Véase el texto en J. F. Blanco R. Azpúrua., Documentos para la Historia..., Tomo II, pp. 272275.

17 Véase en Rafael M. de Labra y Martínez, Los presidentes americanos de las Cortes de Cádiz, Madrid 1912 (Reedición Congreso de Diputados), Madrid, pp. 30-33. 
Con posterioridad, en los días antes de la instalación de las Cortes, el 20 de septiembre de 1810, el Consejo de Regencia cambió las reglas históricas de su constitución, eliminando los «brazos de nobleza y clero», tal como las había convocado el Decreto inicial de la Junta Central. De ello resultó que el 24 de septiembre de 1811, las Cortes se instalaron en la Isla de León formando un solo cuerpo $^{18}$, prescindiendo de la antigua división en estamentos, con 207 diputados. El primero de sus decretos (Decreto $\mathrm{N}^{\circ} 1$ ) fue para declarar «nula, de ningún valor ni efecto la cesión de la Corona que se dice hecha en favor de Napoleón», reconociendo a Fernando VII como Rey ${ }^{19}$. Además, «no conviniendo queden reunidos el Poder Legislativo, el Ejecutivo y el Judiciario», las Cortes Generales se reservaron el Poder Legislativo, y atribuyeron al Consejo de Regencia el ejercicio del Poder ejecutivo ${ }^{20}$.

Pero, como se dijo, la designación de «suplentes americanos» a las Cortes, al contrario de lo que ocurrió en muchas otras provincias americanas, no fue aceptada en las Provincias de Venezuela, las cuales ya se habían declarado independientes de España y desconocían la Regencia. Por ello, si bien en la sesión de instalación de las Cortes en la Isla de León habían concurrido dos diputados supuestamente suplentes por la Provincia de Caracas, los señores Esteban Palacios y Fermín de Clemente que habían sido también reclutados en la Península ${ }^{21}$, lo cierto es que los mismos no habían sido designados por Venezuela. Por ello, dado que ya en Venezuela se había declarado la independencia, los diputados pidieron instrucciones a la Junta Suprema de Caracas, siendo la respuesta de ésta, el $1^{\circ}$ de febrero de 1811, que la reunión de las Cortes «tan ilegal como la formación del Consejo de Regencia» y, por tanto, que «los señores Palacios y Clemente carecían de mandato alguno para representar las Provincias de Venezuela», por lo que «sus actos como diputados eran y serían considerados nulos» ${ }^{22}$. Ya el 23 de enero de 1811, además, la Junta Suprema se había dirigido a los ciudadanos de la Provincia rechazando el nombramiento de tales diputados suplentes, calificando a las Cortes como «las Cortes cómicas de España» ${ }^{23}$.

18 Idem, p. 31.

19 Véase J. F. Blanco y R. Azpúrua, Documentos para la Historia ..., op. cit., Tomo II, p. 657.

20 Véase en Eduardo Roca Roca, América en el Ordenamiento Jurídico de las Cortes de Cádiz, Granada, 1986, p. 193.

21 Véase J. F. Blanco y R. Azpúrua, Documentos para la Historia... op. cit., Tomo II, pp. 656. Véase además, Eduardo Roca Roca, América en el Ordenamiento Jurídico ..., op. cit., pp. 22 y 136.

22 Véase el texto en Gaceta de Caracas, martes 05-02-1811, Caracas, 1959, Tomo II, p. 17. Véase además, C. Parra Pérez, Historia de la Primera República ..., op. cit., Tomo I, p. 484.

23 «Nuestros antiguos tiranos tienden nuevos lazos para prendernos. Una misión vergonzosa y despreciable nos manda que ratifiquemos el nombramiento de los diputados suplentes que 
Con posterioridad a esa fecha, sin embargo, con la excepción de las Provincias de la antigua Capitanía General de Venezuela y de las de la Nueva Granada, lo cierto fue que en el resto de las Provincias americanas fueron electos «diputados propietarios» a las Cortes. En ese proceso, sin embargo, en 1810 sólo habían sido electos tres diputados propietarios por las provincias americanas, por Tlaxcala, Puebla de los Ángeles y Puerto Rico. Además, por lo que respecta a las antiguas provincias de la Capitanía General de Venezuela, se destaca que el 5 de mayo de 1812 se llegó a elegir un diputado por la Provincia de Maracaibo, la cual había sido de las pocas que había permanecido leal al lado realista ${ }^{24}$.

Ahora bien, sólo cinco meses después de la convocatoria a las Cortes en España, el día 11 de junio de 1810, y apenas transcurridos dos meses desde que se constituyera en Caracas la Junta Suprema Conservadora de los derechos de Fernando VII (19 de abril de 1810), la misma, en virtud del carácter poco representativo que tenía en relación con las otras Provincias de la Capitanía General de Venezuela, también procedió a dictar un «Reglamento para elección y reunión de diputados que han de componer el Cuerpo Conservador de los Derechos del Sr. D. Fernando VII en las Provincias de Venezuela» ${ }^{25}$ que se configuró como un Congreso General de diputados de las Provincias de Venezuela, para lo cual también se estableció un sistema de elección indirecta. Este reglamento, sin duda, debe haberse inspirado en la Instrucción para la elección de los diputados a las Cortes de $1810^{26}$.

Mediante este Reglamento se procedió a a convocar al pueblo de todas las Provincias «para consultar su voto» y para que se escogiese «inmediatamente las personas que por su probidad, luces y patriotismo os parecieran dignas de vuestra confianza» para constituir un cuerpo representativo que «evitase los defectos inculpables del actual» y además evitase «la nulidad de carácter público de la

ellos aplicaron a Venezuela. Las Cortes cómicas de España siguen los mismos pasos que su madre la Regencia: ellas, más bien en estado de solicitar nuestro perdón por los innumerables ultrajes y vilipendios con que nos han perseguido, y reducidas a implorar nuestra protección generosa por la situación impotente y débil en que se encuentran, sostienen, por el contrario, las hostilidades contra la América y apuran, impía y bárbaramente, todos los medios para esclavizarnos.» Véase Textos oficiales de la Primera República de Venezuela, Biblioteca de la Academia Nacional de la Historia, 1959, Tomo II, p. 17.

${ }^{24}$ Véase en Rafael M de Labra y Martínez, Los presidentes americanos de las Cortes de Cádiz, cit., p. 34 .

${ }^{25}$ Véase en Textos Oficiales ..., tomo II, pp. 61 a 84; y en Allan R. Brewer-Carías, Las Constituciones de Venezuela, cit., Tomo I, pp. 535-543.

${ }^{26}$ Véase en igual sentido Juan Garrido Rovira, La revolución de 1810, Universidad Monteávila, Caracas 2009, p. 218-219 
Junta Central de España» que adolecía de la misma falta de representatividad. La convocatoria tenía entonces por objeto la necesidad de establecer «un poder Central bien constituido», considerándose que había llegado «el momento de organizarlo», formando «una confederación sólida», con «una representación común.» A tal efecto, la Junta llamó al «ejercicio más importante de los derechos del pueblo» que era «aquel en que los transmite a un corto número de individuos, haciéndolos árbitros de la suerte de todos», convocando a «todas las clases de hombres libres ... al primero de los goces de ciudadano, que es el concurrir con su voto a la delegación de los derechos personales y reales que existieron originariamente en la masa común y que la ha restituido el actual interregno de la monarquía» ${ }^{27}$.

Esta convocatoria a elecciones en las Provincias de Venezuela, en ese momento, por supuesto se realizó contra de las autoridades que existían en España. Si bien, como se dijo, el 12 de enero de 1809, el Ayuntamiento de Caracas había reconocido a la Junta Central como el gobierno supremo del Imperio, ello cambió después de la Revolución de 19 de abril de 1810, de manera que establecida la Junta Suprema de Venezuela, al convocarse la elección de diputados al Congreso General de Diputados en junio de 1810, la misma ya declaraba que era «demasiado evidente que la Junta Central de España no representaba otra parte de la nación que el vecindario de las capitales en que se formaban las Juntas provinciales, que enviaron sus diputados a componerla», y además, que «la Junta Central no pudo transmitir al Consejo de Regencia un carácter de que ella misma carecía», resultando, lo que se denunciaba, como «la concentración del poder en menor número de individuos escogidos, no por el voto general de los españoles de uno y otro mundo, sino por los mismos que habían sido vocales de la Central» $»^{28}$.

Conforme al mencionado Reglamento, en todo caso, se realizaron elecciones en siete de las nueve Provincias de la Capitanía General de Venezuela ${ }^{29}$, habiéndose elegido 44 diputados en las Provincias así: 24 por Caracas; 9 por Barinas; 4 por Cumaná; 3 por Barcelona; 2 por Mérida; uno por Trujillo; y uno por Margarita $^{30}$. Las provincias de Guayana y Maracaibo, sin embargo, no participaron en

27 Idem.

28 Idem.

29 Participaron las provincias de Caracas, Barinas, Cumaná, Barcelona, Mérida, Trujillo y Margarita. Véase José Gil Fortoul, Historia Constitucional de Venezuela, Tomo primero, Berlín 1908, p. 223. Véase J. F. Blanco y R. Azpúrua, J.F. Blanco y R. Azpúrua, Documentos para la historia ..., Tomo II, pp. 413 y 489.

30 Véase C. Parra Pérez, Historia de la Primera República ..., cit., Tomo I, p. 477. 
dicho proceso y permanecieron controladas por las autoridades coloniales, y más bien, como se dijo, en 1812, en la provincia de Maracaibo se llegó a elegir un diputado propietario pero para las Cortes de Cádiz.

En todo caso, aquellos 44 diputados electos en las provincias independientes fueron los que conformaron la Junta o Congreso General que se instaló el 2 de marzo de 1811, momento a partir del cual la Junta Suprema de Caracas cesó en sus funciones. El Congreso había adoptado el principio de la separación de poderes para organizar el nuevo gobierno, reservándose el Poder Legislativo nacional, designando el 5 de marzo de 1811, a tres ciudadanos para ejercer el Poder Ejecutivo Nacional, turnándose en la presidencia por períodos semanales, y constituyendo, además, una Alta Corte de Justicia.

A partir del 25 de junio de 1811, cuando comenzaron las sesiones del Congreso, quedó además claro que el objetivo del mismo era la redacción de una Constitución democrática, republicana y representativa, la cual en definitiva se sancionó el 21 de diciembre de 1811. La misma fue precedida, además, por la formal declaración de los Derechos del Pueblo el $1^{\circ}$ de julio de 1811 y de la también formal declaración de la Independencia el 5 de julio de $1811^{31}$. Seguidamente, además, se sancionaron textos constitucionales en las diversas Provincias (Constituciones Provinciales), en algunos casos antes de la sanción de la Constitución Federal de diciembre de 1811, como el Plan de Gobierno Provisional de la Provincia de Barinas de 26 de marzo de 1811, la Constitución Provisional de la Provincia de Mérida de 31 de julio de 1811 y el Plan de Constitución Provisional Gubernativo de la Provincia de Trujillo de 2 de septiembre de 1811; y en otros casos, después de sancionarse la Constitución Federal, como la Constitución Fundamental de la República de Barcelona Colombiana de 12 de enero de 1812 y la Constitución para el gobierno y administración interior de la Provincia de Caracas del 31 de enero de $1812^{32}$.

Todo lo anterior ocurría antes de que incluso se hubiese promulgado la Constitución de Cádiz el 19 de marzo de 1812, y en paralelo a las reuniones de las Cortes de Cádiz que como se dijo, se habían instalado el 24 de septiembre de 1810, y en las cuales también se había comenzado a delinear una Constitución Monárquica de democracia representativa.

31 Véase los textos en Allan R. Brewer-Carías, Las Constituciones de Venezuela cit., Tomo I, pp. 545 ss.

32 Véase los textos en Las Constituciones Provinciales («Estudio Preliminar» por Ángel Bernardo Brices), Academia Nacional de la Historia, Caracas 1959, pp. 334 ss. 


\section{LA CONSOLIDACIÓN DEL DESENCUENTRO: LA GUERRA DECRETADA POR LA REGENCIA Y CONTINUADA POR LAS CORTES DE CÁDIZ, CONTRA LAS PROVINCIAS DE VENEZUELA}

Como se dijo, la Constitución Federal para los Estados de Venezuela se sancionó el 21 de diciembre 1811 con la cual se constituyó definitivamente en lo que fueron las Provincias de la Capitanía General de Venezuela, un Estado nuevo e independiente de España, donde se había desconocido a las propias Cortes de Cádiz muchos meses antes de la sanción de la Constitución gaditana de 1812. Con la nueva constitución del Estado, en todo caso, las antiguas formas institucionales de la Colonia comenzaron a ser sustituidas por las nuevas instituciones republicanas establecidas en cada una de las Provincias, que se fueron incluso regulando en las Constituciones Provinciales y, todas, bajo una organización nacional conforme a la Constitución Federal de diciembre de 1811.

Como se dijo, aún antes de sancionarse la Constitución Federal, ante la Orden de bloqueo de las costas de Venezuela decidido el 1 de agosto de $1810^{33}$, y la guerra declarada por España contra las Provincias, el Congreso General no sólo ya había denunciado al Consejo de Regencia, sino a las propias Cortes de Cádiz. Es decir, la ruptura constitucional derivada de la declaración de Independencia de las provincias de Venezuela no sólo se había operado de parte de la Junta Suprema de Caracas en relación con el Consejo de Regencia, sino que continuó con respecto de las Cortes de Cádiz, las cuales, integradas como ya estaban con diputados suplentes y luego principales americanos, además, se involucraron directamente en el conflicto contra Venezuela. Por ello, en Venezuela se las consideraron, como se dijo, como «ilegítimas y cómicas», rechazándose en ellas toda representación de las Provincias de Venezuela que se pudiera atribuir a cualquiera, comenzando por los dos «suplentes» que habían sido designados en Cádiz.

El Congreso General, en efecto, dejó muy clara su posición en un excepcional documento titulado «Manifiesto que hizo al mundo la Confederación de Venezuela en la América Meridional» de fecha 30 de julio de 1811 (en lo adelante, el Manifiesto que bizo al mundo de 1811) ${ }^{34}$, al expresar que irritaba «ver tan-

${ }^{33}$ La Orden de Bloqueo de 1 de agosto de 1810 decía: «declarar como declara en estado de rigoroso bloqueo la provincia de caracas: mandando que ningún buque nacional ni extranjero pueda arribar a sus puertos, so pena de ser detenido por los cruceros y buques de S.M.». Véase en Garrido Rovira, La Revolución de 1810, Universidad Monteávila, Caracas 2009, p. 1999-200.

${ }^{34}$ Publicado en 1812 en el libro (edición bilingue), Interesting Official Documents Relating to the United Provinces of Venezuela, W. Glidon, Rupert-Street, Haymarket, para Longman and Co. Paternoster-Row; Durlau, Soho-Square; Hartding, St. Jame's Street; y W. Mason, No. 6, Holywell Street, Strand, \&c. \&c, London 1812. Véase el texto en español, en el libro La Constitución Federal 
ta liberalidad, tanto civismo y tanto desprendimiento en las Cortes con respecto a la España desorganizada, exhausta y casi conquistada; y tanta mezquindad, tanta suspicacia, tanta preocupación y tanto orgullo con América, pacífica, fiel, generosa, decidida a auxiliar a sus hermanos y la única que puede no dejar ilusorios, en lo esencial, los planes teóricos y brillantes que tanto valor dan el Congreso español;» denunciando que «a ninguna de las provincias rendidas o contentas con la dominación francesa se le ha tratado como a Venezuela;» «ninguna de ellas ha sido hasta ahora declarada traidora, rebelde y desnaturalizada como Venezuela, y para ninguna de ellas se ha creado una comisión pública de amotinadores diplomáticos para armar españoles contra españoles, encender la guerra civil e incendiar todo lo que no se puede poseer o dilapidar a nombre de Fernando VII» ${ }^{35}$.

En el conflicto abierto, por ejemplo, las Cortes llegaron incluso a comienzos de 1812, «premiar» formalmente a las Provincias de la antigua Capitanía General de Venezuela que no se habían sumado al movimiento independentista (Maracaibo, Guayana y la ciudad de Coro), ni habían elegido diputados al Congreso General de Venezuela de 1811. Así fue que por ejemplo, las Cortes ya integradas incluso con «diputados principales» americanos, mediante el Decreto CXXXIII de 6 de febrero de 1812, concedieron a la ciudad de Guayana el adorno de su escudo de armas con trofeos de cañones, balas, fusiles, bandera y demás insignias militares, como premio por haber apresado a los rebeldes de Nueva Barcelona en la acción del 5 de septiembre de 1811 y por Decreto CCXII de 8 de diciembre de 1812 , le concedieron el título de «muy noble y muy leal, con motivo de los sucesos de Venezuela ocurridos del 15 al 16 de marzo de 1812; mediante Decreto CCXXXVVII de 21 de marzo de 1813, distinguieron a la ciudad de Coro con el título de «muy noble y leal» y escudo alusivo, otorgándose la distinción de «Constancia de Coro» a favor de los Capitulares por el comportamiento de la ciudad en las turbulencias que habían «inflingido a varias provincias de Venezuela» y su defensa frente a los insurgentes de Caracas en 28 de noviembre de 1812; y que mediante Decreto CCXXXVIII de 21 de marzo de 1813 la ciudad de Maracaibo recibiera el título de «muy noble y leal» por las mismas

de Venezuela de 1811 y Documentos Afines («Estudio Preliminar» por Caracciolo Parra-Pérez), Biblioteca de la Academia Nacional de la Historia, Sesquicentenario de la Independencia, Caracas 1952, pp. 105-148. Véase los comentarios al Manifiesto que bizo al mundo en Ángel Francisco Brice, El Constituyente de Venezuela durante el año 1812, Ediciones de la Presidencia, caracas 1970, pp. 17-30.

35 Véase en La Constitución Federal de Venezuela de 1811..., cit., pp.105-148. 
razones de Coro, otorgándose a los miembros del Ayuntamiento la «Constancia de Maracaibo» ${ }^{36}$.

Sobre esas Cortes de Cádiz, el Manifiesto que bizo al mundo del Congreso General de 1811 explicó que luego de los «rápidos y raros gobiernos» que se habían sucedido en España desde la Junta de Sevilla, «se apeló a una aparente liberalidad», y «se aceleraron y congregaron tumultuariamente las Cortes que deseaba la nación, que resistía el gobierno comercial de Cádiz y que se creyeron al fin necesarias para contener el torrente de la libertad y la justicia, que rompía por todas partes los diques de la opresión y la iniquidad en el nuevo mundo.» ${ }^{37} \mathrm{Sin}$ embargo, al analizar su composición, el Congreso General, en el Manifiesto que bizo al mundo, se preguntó incrédulo sobre «por qué especie de prestigio funesto para España se cree que la parte de la nación que pasa el océano o nace entre los trópicos adquiere una constitución para la servidumbre, incapaz de ceder a los conatos de la libertad;» afirmando como harto estaban demostrados en los papeles públicos de la Provincia de Venezuela, todos:

los vicios de que adolecen las Cortes con respecto a la América y el ilegítimo e insultante arbitrio adoptado por ellas para darnos una representación que resistiríamos, aunque fuésemos, como vociferó la Regencia, partes integrantes de la nación y no tuviésemos otra queja que alegar contra su gobierno sino la escandalosa usurpación que hace de nuestros derechos, cuando más necesita de nuestros auxilios $^{38}$.

El Congreso General destacó en el Manifiesto que bizo al mundo que a las Cortes habría llegado la noticia de las razones que había dado la Junta de Caracas «a su pérfido enviado» ${ }^{39}$, cuando «frustradas las misiones anteriores, inutilizadas las cuantiosas remesas de gacetas llenas de triunfos, reformas, heroicidades y lamentos, y conocida la ineficacia de los bloqueos, pacificadores, escuadras y expediciones», en la Península:

se creyó que era necesario deslumbrar el amor propio de los americanos, sentando bajo el solio de las Cortes a los que ellos no habían nombrado, ni podían nombrar los que crearon suplentes con los de las provincias ocupadas, sometidas y contentas con la dominación francesa ${ }^{40}$.

36 Véase el texto de los Decretos en Eduardo Roca Roca, América en el Ordenamiento Jurídico ...., op. cit., pp. 79-80.

37 Véase en La Constitución Federal de Venezuela de 1811 ..., cit., pp.105-148.

38 Idem, pp.105-148.

39 Se refirió al Congreso General en el Manifiesto que hizo al mundo a la «conducta execrable y notoria de Montenegro, desnaturalizado por el Gobierno Español.» En Idem, pp.105-148.

40 Véase en La Constitución Federal de Venezuela de 1811..., cit., pp.105-148. 
Así, denunció el Manifiesto que bizo al mundo del Congreso General de 1811, que:

se escribió el elocuente manifiesto que asestaron las Cortes en 9 de enero de este año [1811] a la América, ${ }^{41}$ con una locución digna de mejor objeto; bajo la brillantez del discurso, se descubría el fondo de la perspectiva presentada para alucinarnos. Temiendo que nos anticipásemos a protestar todas estas nulidades, se empezó a calcular sobre lo que se sabía, para no aventurar lo que se ocultaba. Fernando, desgraciado, fue el pretexto que atrajo a sus pseudo-representantes los tesoros, la sumisión y la esclavitud de la América, después de la jornada de Bayona; y Fernando, seducido, engañado y prostituido a los designios del Emperador de los franceses, es ya lo último a que apelan para apagar la llama de la libertad que Venezuela ha prendido en el continente meridional ${ }^{42}$.

Pero a pesar de tal manifestación de las Cortes «destinada a conmover la América», el Congreso General indicó en el Manifiesto que bizo al mundo que era del convencimiento «que entre las cuatro paredes de las Cortes se desatienden de nuestra justicia, se eluden nuestros esfuerzos, se desprecian nuestras resoluciones, se sostienen a nuestros enemigos, se sofoca la voz de nuestros imaginarios repre-

${ }^{41}$ Se refería al «Manifiesto de las Cortes generales y extraordinarias a la Nación» de 09-011811, donde se daban las razones para la independencia de España frente a las pretensiones de Napoleón. Véase el texto publicado en El Mercurio Venezolano, Vol I, Caracas, febrero 1811. Véase el texto de el periódico en versión facsimilar en http://cic1.ucab.edu.ve/hmdg/bases/hmdg/textos/Mercurio/Mer_Febrero 1811.pdf. Debe destacarse que el redactor de El Mercurio en 1811 era precisamente Francisco Isnardy, Secretario del Congreso General, quien como tal firmó el Manifiesto del Congreso de 1811. En la nota que precede el texto del Manifiesto de las Cortes generales, sin duda de la pluma de Isnardy, se redactó el siguiente texto parodiando lo que podría haber dicho Napoleón, y cuyo texto se recoge en el Manifiesto del Congreso General, al decirse que: «En uno de nuestros periódicos («Mercurio Venezolano», de febrero de 1811), hemos descubierto el verdadero espíritu del Manifiesto en cuestión, reducido al siguiente raciocinio que puede mirarse como su exacto comentario «La América se ve amenazada de ser víctima de una nación extraña o de continuar esclava nuestra; para recobrar sus derechos y no depender de nadie, ha creído necesario no romper violentamente los vínculos que la ligaban a estos pueblos; Fernando ha sido la señal de reunión que ha adoptado el Nuevo Mundo, y hemos seguido nosotros; él está sospechado de connivencia con el Emperador de los franceses y si nos abandonamos ciegamente a reconocerlo demos un pretexto a los americanos que nos crean aún sus representantes para negarnos abiertamente esta representación; puesto que ya empiezan a traslucirse en algunos puntos de América estos designios, manifestemos de antemano nuestra intención de no reconocer a Fernando sino con ciertas condiciones; éstas no se verificarán jamás y mientras que Fernando, ni de hecho ni de derecho, es nuestro Rey, lo seremos nosotros de la América, y este país tan codiciado de nosotros y tan difícil de mantener en la esclavitud, no se nos irá tan pronto de las manos.»

42 Véase en La Constitución Federal de Venezuela de 1811..., cit., pp.105-148. 
sentantes, se renueva para ellos la Inquisición ${ }^{43}$, al paso que se publica la libertad de imprenta y se controvierte si la Regencia pudo declararnos libres y parte integrante de la nación» ${ }^{44}$.

El conflicto, en todo caso, fue mutuo, y era evidente que en el mismo, las autoridades españolas no renunciaron junto con los realistas locales, al control político de la antigua Capitanía General de Venezuela, por lo que como se dijo, para agosto de 1810, el Consejo de Regencia había decretado el bloqueo de las costas de Venezuela, y en enero de 1811, el mismo Consejo había designado a Antonio Ignacio de Cortavarría como Comisionado Real para «pacificar» a los venezolanos, estableciéndose en Puerto Rico, lo que la Junta Suprema denunciaba en una Proclama del 25 de enero de 1811, como un «Club de la tiranía y del despotismo» ${ }^{45}$. Antes, incluso, la Suprema Junta de Caracas el 25 de diciembre de 1811, ya había contestado al mismo Comisionado regio Cortavarría, la nota que este había enviado desde Puerto Arico el 7 de diciembre de 1810, cuestionando su misión de «pacificación de las provincias de Venezuela y restablecimiento del orden», indicándole que:

«los mismos fundamentos que hemos tenido para desconocer a la Regencia de Cádiz como reina o emperatriz de estas provincias, nos obligan ahora a desconocer la comisión de V.S, sus cédulas, sus despachos, sus proclamas y demás papeles que está expidiendo en esa isla, como si fuese Fernando VII, pero contra la voluntad de este desgraciado Monarca» ${ }^{46}$,

La Junta denunciaba, además «el indigno tratamiento de insurgentes o rebeldes, la fuerza, las amenazas, el decreto de bloqueo» como respuesta a los partes oficiales dirigidos sobre las ocurrencias del 19 de abril; que «la Regencia, estimulada con los sucesos de Venezuela forma Cortes Extraordinarias en la Isla de león, semejantes a las de Bayona, nombra diputados a su arbitrio, escoge dos suplentes por estas provincias cuando ya tenía declarados a sus puertos en estado de bloqueo;» y que se pretendiera que las Provincias dependieran de Fernando Miyares «que se dice Capitán general de Venezuela» y cuyo nombramiento se denunciaba como nulo «hechura del favorito de Carlos IV ${ }^{47}$.

43 En el Manifiesto que bizo al mundo se indicó que había «noticias positivas de que el Sr. Mejía, Suplente de Santa Fe, ha sido encerrado en la Inquisición por su liberalidad de ideas.» Idem.

${ }^{4}$ Id

45 Véase Textos Oficiales de la primera República de Venezuela, Biblioteca de la Academia de Ciencias Políticas y Sociales, Caracas 1982, Tomo II, p. 18.

${ }^{46}$ Id. Tomo I, pp. 259-269.

47 Véase Textos Oficiales de la primera República de Venezuela, Biblioteca de la Academia de Ciencias Políticas y Sociales, Caracas 1982, Tomo I, pp. 259-269. 
Sobre la persecución contra la Provincia que se desató «desde la isla de Puerto Rico» y que no cesó con la integración de las Cortes, en el Manifiesto que bizo al mundo del Congreso General de 1811 se dio cuenta de que «Meléndez, nombrado Rey de Puerto Rico por la Regencia», quedó:

«por un decreto de las Cortes con la investidura equivalente de gobernador, nombres sinónimos en América, porque ya parecía demasiado monstruoso que hubiese dos reyes en una pequeña isla de las Antillas españolas. Cortabarría solo bastaba para eludir los efectos del decreto, dictado sólo por un involuntario sentimiento de decencia. Así fue que cuando se declaraba inicua, arbitraria y tiránica la investidura concedida por la Regencia a Meléndez y se ampliaba la revocación a todos los países de América que se hallasen en el mismo caso que Puerto Rico, nada se decía del plenipotenciario Cortabarria, autorizado por la misma Regencia contra Venezuela, con las facultades más raras y escandalosas de que hay memoria en los fastos del despotismo orgánico ${ }^{48}$.

Y precisamente, después del decreto de las Cortes, como se denunció en el Manifiesto que bizo al mundo del Congreso General de 1811, fue que se sintieron «más los efectos de la discordia, promovida, sostenida y calculada desde el fatal observatorio de Puerto Rico;» denunciándose que habían sido «asesinados inhumanamente los pescadores y costaneros en Ocumare por los piratas de Cortabarria»; que habían «sido bloqueadas, amenazadas e intimadas Cumaná y Barcelona»; que se habían «organizado y tramado una nueva y sanguinaria conjuración contra Venezuela, por el vil emisario introducido pérfidamente en el seno pacífico de su patria para devorarla»; que se había «alucinado a la clase más sencilla y laboriosa de los alienígenas de Venezuela»; y que «por las sugestiones del pacificador de las Cortes, después del decreto de éstas», se había turbado e interrumpido «la unidad política de nuestra Constitución», promoviéndose la discordia entre las Provincias:

para que en un mismo día quedase sumergida Venezuela en la sangre, el llanto y la desolación, asaltada hostilmente por cuantos puntos han estado al alcance de los agitadores, que tiene esparcidos contra nosotros el mismo Gobierno que expidió el decreto a favor de Puerto Rico y de toda la América. El nombre de Fernando Vil es el pretexto con que va a devorarse el Nuevo Mundo; si el ejemplo de Venezuela no hace que se distingan, de hoy más, las banderas de la libertad clara y decidida, de las de la fidelidad maliciosa y simulada ${ }^{49}$.

En todo caso, la invasión de Venezuela desde el Cuartel General colonial que se

48 Idem.

49 Idem. 
había instalado en Puerto Rico, se materializó en febrero de 1812, cuando dos meses después de sancionada la Constitución Federal de diciembre 1811, Domingo de Monteverde, designado Comandante General del Ejercito de Su Majestad Católica y quien luego asumiría de hecho el título de Capitán General de las Provincias de Venezuela, desembarcó en Coro e inició la campaña de recuperación realista de la República; desembarco que se produjo en las mismas costas donde seis años antes habría tocado tierra brevemente Francisco de Miranda (1806).

Con ello, todo el proceso de estructuración del nuevo orden constitucional republicano quedó a medio hacer, pues apenas se había instalado el nuevo gobierno de la Federación en la capital Valencia, el 1 de marzo de 1812, la reacción realista se comenzó a sentir con Monteverde a la cabeza, lo que fue facilitado por los efectos devastadores del terremoto que desoló a Caracas el 24 del mismo mes de marzo de 1812, que los Frailes y el Arzobispo de Caracas atribuyeron a un castigo de Dios por los hechos de la Revolución de Caracas ${ }^{50}$. En todo caso, lo cierto fue que a la devastación física y moral de las Provincias, con la invasión de las tropas españolas se le agregó la total devastación institucional de las mismas.

La amenaza de Monteverde y la necesidad de defender la República, en efecto, llevaron al Congreso el 4 de abril de 1812, a delegar en el Poder Ejecutivo todas las facultades necesarias ${ }^{51}$, y éste, el 23 de abril de 1812, nombró como Generalísimo a Francisco de Miranda, con poderes dictatoriales.

En esta forma, la guerra de independencia obligó, con razón, a dejar de un lado la Constitución, y fue el Secretario de Guerra José de Sata y Bussy, quien le comunicó al Teniente General Francisco de Miranda, en correspondencia dirigida ese mismo día 23 de abril de 1812, que:

Acaba de nombraros el Poder Ejecutivo de la Unión, General en Jefe de las armas de toda la Confederación Venezolana, con absolutas facultades para tomar cuantas providencias juzguéis necesarias a salvar nuestro territorio invadido por los enemigos de la libertad colombiana; y bajo este concepto, no os sujeta ley alguna ni reglamento de los que hasta ahora rigen estas Repúblicas, sino que al contrario, no consultaréis más que la Ley suprema de salvar la patria; y a este efecto os delega el Poder de la Unión sus facultades naturales y las extraordinarias que le confirió la representación nacional por decreto de 4 de este mes, bajo vuestra responsabilidad $^{52}$.

50 Véase J.F. Blanco y R. Azpúrua, Documentos para la Historia..., Tomo III, pp. 614 y ss.

51 Véase Libro de Actas del Congreso de Venezuela 1811-1812, Biblioteca de la Academia Nacional dé la Historia, Tomo II,. Caracas, 1959, pp. 397 a 399.

52 Ver Archivo del General Miranda, Tomo XXIX, La Habana, 1950, pp. 396 y 397. Véase el texto en Allan R. Brewer-Carías, Las Constituciones de Venezuela, cit, Tomo I, p. 581. 
En la sesión del Congreso del 4 de abril de 1812, se había acordado que «la medida y regla» de las facultades concedidas al Poder Ejecutivo fuera la salud de la Patria; y que siendo esa la suprema ley, «debe hacer callar las demás» ${ }^{53}$; pero a la vez, se acordó participar a las «Legislaturas Provinciales» la vigencia de la Constitución Federal sin perjuicio de las facultades extraordinarias al Poder Ejecutivo $^{54}$.

El Congreso, el mismo 4 de abril de 1812, además, había exhortado a las mismas «Legislaturas provinciales» que obligaran y apremiasen a los diputados de sus provincias a que sin excusa ni tardanza alguna se hallaren en la ciudad de Valencia para el 5 de julio de 1812, para determinar lo que fuera más conveniente a la causa pública ${ }^{55}$. Esta reunión nunca se pudo realizar.

En esta forma, a los pocos meses de sancionada la Constitución Federal de 1811, por la necesidad de salvar la República, se produjo la primera ruptura del hilo constitucional. La dictadura duró poco, pues el 25 de julio de 1812 se firmó la Capitulación de Miranda y la aceptación por parte del Gobierno y todos los poderes del Estado, mediante un Armisticio, de la ocupación del territorio de la provincia de Caracas por Monteverde ${ }^{56}$. El coronel Simón Bolívar, quien había tenido a su cargo la plaza militar de Puerto Cabello, la perdió y, a mediados de julio, antes de la Capitulación, comunicó los sucesos a Miranda. Entre las múltiples causas de la caída de la Primera República estuvo, sin duda, la pérdida de Puerto Cabello.

Monteverde, en todo caso, desconoció los términos del Armisticio, siendo una de las consecuencias de esto, que Miranda hubiera sido detenido y entregado por sus subalternos, entre ellos Bolívar, a comienzos de agosto de 1811, habiendo sido enviado a la prisión de La carraca en Cádiz, donde moriría en 1816. Bolívar, por su parte, a fines de agosto, logró salir de La Guaira con un salvoconducto emitido por las nuevas autoridades, hacia Curazao y luego a Cartagena ${ }^{57}$.

La caída de la primera República de Venezuela se materializó, sin duda, con la Capitulación del General Francisco de Miranda el 25 de julio de 1812, con lo que el orden republicano que se había comenzado a construir fue totalmente

53 Véase Libro de Actas del Congreso de Venezuela..., op. cit., pág. 398.

${ }^{54}$ Idem, p. 400.

55 Ibídem, pp. 398-399.

56 Véase los documentos en J.F. Blanco y R. Azpúrua, Documentos para la Historia...., pp. 679 y ss. Además, en José de Austria, Bosquejo de la Historia Militar de Venezuela, Biblioteca de la Academia Nacional de la Historia, Tomo I, Caracas 1960, pp. 340 y ss. (José de Austria fue contemporáneo del proceso de Independencia; había nacido en Caracas en 1791).

57 Véase Giovanni Meza Dorta, Miranda y Bolivar. Dos visiones, Ed. Bid \& co. Editor, Caracas 2007, p. 152 ss 
demolido, abrogándose por supuesto la Constitución Federal de 1811, e ignorándose además incluso el texto de la misma Constitución de Cádiz que debía jurarse en las provincias ocupadas. Había recomenzado así, en la Provincia, trescientos años después del Descubrimiento, la aplicación de la «ley de la conquista», destruyéndose además, la memoria historia del país con el saqueo de los Archivos de la Provincia, y la destrucción y desaparición de los propios documentos de la independencia.

Una vez abrogada la Constitución de 1811 por la fuerza militar, las autoridades invasoras debían en cambio procurar que en Venezuela se publicase la recién sancionada Constitución de Cádiz, para lo cual el Capitán General Fernando Mijares, quién había sido recién nombrado Gobernador de la antigua Provincia de Venezuela, cargo que no llegó a ejercer efectiva y materialmente jamás, el 13 de agosto de 1812 le remitió a Monteverde desde Puerto Cabello, veinte ejemplares del texto constitucional monárquico, con las correspondientes órdenes y disposiciones que habían dado las Cortes para su publicación y observancia $^{58}$.

Y así lo hizo Monteverde, pero «a la manera militar», el 21 de noviembre de 1812, y luego en Caracas, el 3 de diciembre de 1812, asumiendo sin embargo un poder omnímodo contrario al texto constitucional gaditano ${ }^{59}$. Sobre la Constitución de Cádiz, o más bien, sobre su no aplicación en Venezuela, el mismo Monteverde informaría con toda hostilidad al gobierno de la Metrópoli, diciéndole que si había llegado a publicar la Constitución de Cádiz, ello había sido «por un efecto de respeto y obediencia, no porque consideré a la provincia de Venezuela merecedora todavía de que participase de los efectos de tan benigno código» ${ }^{60}$.

Por ello, durante toda su campaña en Venezuela entre 1812 y 1813, Monteverde desconoció la exhortación de amnistía que habían hecho las propias Cortes de Cádiz en octubre de 1810; desconoció, como se dijo, los términos de la Capitulación que había firmado con Francisco de Miranda el 25 de julio de 1812; desconoció las previsiones de la propia Constitución de 1812; y desconoció las decisiones judiciales adoptadas por la Audiencia de Caracas con motivo de la persecución política que aquél desarrolló. Monteverde aplicó, en fin, «la ley de la

58 Véase José de Austria, Bosquejo de la Historia militar..., op. cit., Tomo I, p. 364.

59 Véase Manuel Hernández González, «La Fiesta Patriótica. La Jura de la Constitución de Cádiz en los territorios no ocupados (Canarias y América) 1812-1814», en Alberto Ramos Santana y Alberto Romero Ferrer (eds), 1808-1812: Los emblemas de la libertad, Universidad de Cádiz, Cádiz 2009, pp. 104 ss.

${ }^{60}$ Véase José de Austria, Bosquejo de la Historia militar..., op. cit., Tomo I, p. 370. 
conquista» $^{61}$, y ello fue lo que en definitiva premiaron las Cortes de Cádiz al haberlo felicitado mediante Orden de 21 de octubre de 1812, a él y a las tropas bajo su mando, «por los importantes y distinguidos servicios prestados en la pacificación de la Provincia de Caracas» ${ }^{62}$.

De estos acontecimientos, por lo demás, dio cuenta Simón Bolívar en su «Exposición sucinta de los hechos del Comandante español Monteverde, durante el año de su dominación en las Provincias de Venezuela» de fecha 20 de septiembre de 1813:

Pero hay un hecho, que comprueba mejor que ninguno la complicidad del Gobierno de Cádiz. Forman las Cortes la constitución del Reino, obra por cierto de la ilustración, conocimiento y experiencia de los que la compusieron. La tuvo guardada Monteverde como cosa que no importaba, o como opuesta a sus ideas y las de sus consejeros. Al fin resuelve publicarla en Caracas. La publica ¿y para qué? No sólo para burlarse de ella, sino para insultarla y contradecirla con hechos enteramente contrarios. Convida a todos, les anuncia tranquilidad, les indica que se ha presentado el arca de paz, concurren los inocentes vecinos, saliendo muchos de las cavernas en que se ocultaban, le creen de buena fe y, como el fin era sorprender a los que se le habían escapado, por una parte se publicaba la Constitución española, fundada en los santos derechos de libertad, propiedad y seguridad, y por otra, el mismo día, andaban partidas de españoles y canarios, prendiendo y conduciendo ignominiosamente a las bóvedas, a los incautos que habían concurrido a presenciar y celebrar la publicación.

Es esto un hecho tan notorio, como lo son todos los que se han indicado en este papel, y se explanarán en el manifiesto que se ofrece. En la provincia de Caracas, de nada vale la Constitución española; los mismos españoles se burlan de ella y la insultan. Después de ella, se hacen prisiones sin sumaria información; se ponen grillos y cadenas al arbitrio de los Comandantes y Jueces; se quita la vida sin formalidad, sin proceso $^{63} \ldots$

En Venezuela, por tanto, la situación era de orden fáctico pues el derrumbamiento del gobierno constitucional fue seguido en paralelo, por el desmembramiento de las instituciones coloniales. Por ello, durante toda su campaña en Venezuela en 1812 y 1813 , Monteverde desconoció la exhortación que habían hecho las Cortes de Cádiz, en octubre de 1810, sobre la necesidad de que en las provincias de Ultramar donde se hubiesen manifestado conmociones (sólo era el

61 Idem.

62 Véase en Eduardo Roca Roca, América en el Ordenamiento Jurídico..., op. cit., p. 81.

63 Véase José de Austria, Bosquejo de la Historia militar..., Tomo II, pp. 111 a 113. 
caso de Caracas), si se producía el «reconocimiento a la legítima autoridad soberana» establecida en España, debía haber «un general olvido de cuanto hubiese ocurrido indebidamente» ${ }^{64}$. La reacción de los patriotas contra la violación por Monteverde de la Capitulación de Miranda, llevó al mismo Monteverde a constatar, en representación dirigida a la Regencia el 17 de enero de 1813, que:

desde que entré en esta Capital y me fui imponiendo del carácter de sus habitantes, conocí que la indulgencia era un delito y que la tolerancia y el disimulo hacían insolentes y audaces a los hombres criminales ${ }^{65}$

Agregaba su apreciación sobre «la frialdad que advertí el día de publicación de la Constitución y la falta de concurrencia a actos públicos de alegría», lo que lo apartaron de sus intentos de gobernar con dulzura y afabilidad. Convocó a una Junta que, en consecuencia, ordenó «la prisión de los que se conocían adictos a la revolución de 1810»,rebelándose contra la propia Real Audiencia que «había puesto en libertad algunos mal vistos del pueblo que irritaban demasiado mi fueros», ordenando a los Comandantes militares que no liberaran los reos a la justicia $^{66}$.

Por ello, el 30 de diciembre de 1812, en oficio dirigido al Comandante Militar de Puerto Cabello, Monteverde, en desprecio del Tribunal, le ordenaba:

Por ningún motivo pondrá usted en libertad hombre alguno de los que estén presos en esa plaza por resulta de la causa de infidencia, sin que preceda orden mía, aún cuando la Real Audiencia determine la soltura, en cuyo caso me lo participará Ud. para la resolución que corresponde ${ }^{67}$.

La Real Audiencia acusó a Monteverde de infractor de las leyes, por lo que decía en una representación, que «se me imputa que perturbo estos territorios, los inquieto y pongo en conmoción, violando las leyes que establecen su quietud ${ }^{68}$.

Monteverde concluyó su representación declarando su incapacidad de gobernar la Provincia, señalando que:

así como Coro, Maracaibo y Guayana merecen estar bajo la protección de la Constitución de la Monarquía, Caracas y demás que componían su Capitanía Ge-

${ }^{64}$ Véase el Decreto V, 15-10-10, en Eduardo Roca Roca, América en el Ordenamiento Jurídico..., p. 199.

65 Véase el texto en J.F. Blanco y R. Azpúrua, Documentos para la Historia...., Tomo IV, pp. 623-625.

66 Idem.

67 Véase el texto en José de Austria, Documentos para la Historia.... Tomo I, pp. 365 y 366.

68 Véase en J.F. Blanco y R. Azpúrua, Documentos para la Historia..., Tomo IV, pp. 623-625. 
neral, no deben por ahora participar de su beneficio hasta dar pruebas de haber detestado su maldad, y bajo este concepto deben ser tratadas por la ley de la conquista; es decir, por la dureza y obras según las circunstancias; pues de otro modo, todo lo adquirido se perderá ${ }^{69}$.

En Venezuela, por tanto, los años de 1813 y 1814, fueron de guerra total, de guerra a muerte, durante los cuales Monteverde comandó una dictadura militar ${ }^{70}$ represiva y despiadada contra los que habían tomado partido por la Revolución de 1810. Eso explica las palabras de Bolívar, desde Mérida, el 8 de julio de 1813:

Las víctimas serán vengadas: los verdugos exterminados. Nuestra bondad se agotó ya, y puesto que nuestros opresores nos fuerzan a una guerra mortal, ellos desaparecerán de América, y nuestra tierra será purgada de los monstruos que la infestan. Nuestro odio será implacable, y la guerra será a muerte ${ }^{71}$.

En las Provincias de Venezuela, en consecuencia, instalado Monteverde en el poder, dejó de aplicarse la Constitución Federal de 1811 ni no tuvo aplicación la Constitución de Cádiz; es decir, no había Constitución alguna que no fuera el mando militar de realistas y patriotas. Conforme la guerra corría por todo el territorio, Monteverde, Boves y sus seguidores gobernaron con la más brutal ley de la conquista; y Bolívar y los patriotas, por su parte, gobernaron con la ley dictatorial del «plan enérgico» del «poder soberano» de quien había sido proclamado Libertador, y que, como decía el propio Bolívar, «tan buenos sucesos me ha proporcionado» ${ }^{72}$.

Coincidiendo con la brutal guerra que se sucedió en Venezuela en 1813 y 1814, Fernando VII en cuyo nombre se había adoptado la Constitución de Cádiz de 1812, una vez que el 22 de marzo de 1814 entró a España luego de la firma del Tratado de Valencay de 1813 mediante el cual Napoleón lo reconoció como Rey, por Real Decreto de 4 de mayo de 1814 expedido en Valencia, restauró la Monarquía Absoluta, negándose a jurar la Constitución de Cádiz que durante dos años le había mantenido su Monarquía, anulándola junto con los demás actos constitucionales que las Cortes habían dictado a su amparo, diciendo que quedaban «nulos y de ningún valor ni efecto, ahora ni en tiempo alguno, como si no hubiesen pasado jamás tales actos, y se quitasen de en medio del tiempo.» Para hacer esto, Fernando VII reaccionó contra las propias Cortes, denunciando que se habían constituido «de un modo jamás usado en España aun en los tiempos más

69 Idem.

70 Véase J. Gil Fortoul, Historia Constitucional..., Tomo I, p. 214.

71 Idem, Tomo I, p. 216.

72 Idem, Tomo I, p. 221. 
arduos» al no haber participado en la misma «los Estados de la Nobleza y Clero, aunque la Junta Central lo había mandado», y además, considerando que los diputados a las Cortes, desde el mismo día de su instalación, lo habían «despojado de su soberanía» al haberla atribuido «nominalmente a la Nación, para apropiársela así ellos mismos, y dar a ésta después, sobre tal usurpación, las Leyes que quisieron ${ }^{73}$.

En esta forma, habiéndose sentado las bases del constitucionalismo venezolano antes de la sanción de la Constitución de Cádiz, la cual no tuvo efectiva aplicación en Venezuela, salvo formalmente por imposición en medio de la guerra, la misma no tuvo ni pudo tener influencia alguna, ni siquiera en constitucionalismo posterior. Era demasiado española, y Venezuela había declarado la guerra a todo lo español; y por su parte, España le había declarado la guerra a los venezolanos, comandada por la Regencia y las propias Cortes, guerra que, además, una vez reinstaurada la Monarquía, se materializó físicamente en 1815 con el envío de la mayor expedición armada jamás antes enviada a América desde España, la compuesta por más de 15.000 hombres al mando del Mariscal de Campo Pablo Morillo, precisamente para pacificar a las Provincias de Venezuela ${ }^{74}$.

\section{LA CONVERGENCIA CONSTITUCIONAL ENTRE CARACAS (1811) Y CÁDIZ (1812), A PESAR DEL DESENCUENTRO, POR LA RECEPCIÓN DE LOS MISMOS PRINCIPIOS DEL CONSTITUCIONALISMO MODERNO}

A pesar de todo el desencuentro que acompañó el proceso constituyente venezolano y gaditano, sin embargo, lo cierto fue que estuvieron influidos por los mismos principios del constitucionalismo moderno que habían derivado de las Revoluciones francesa y americana, y fueron incorporados en la Constitución Federal de los Estados de Venezuela de 1811 y en la Constitución de Cádiz de 1812. Y ello, por supuesto, a pesar de que para cuando se iniciaron dichos procesos constituyentes en Cádiz y en Venezuela, a partir de 1810, ya la República francesa había dejado de existir, pues había sido suprimida en 1808; la Declaración de Derechos no tenía rango constitucional, que había perdido en 1799; y la propia Revolución había cesado en 1795. Del caos institucional que surgió de la misma, vino la dictadura napoleónica, primero a través del Consulado provisorio (1799) y vitalicio (1802), y luego como Emperador (1804); y posteriormente,

73 Véase el texto en : http://www.historiasiglo20.org/HE/texto-decretovalenciafernandoVII.htm

${ }^{74}$ Véase José Gil Fortoul, Historia Constitucional..., Tomo I, p. 237. 
cuando fue encarcelado, a partir de 1814, ocurrió la restauración de la Monarquía habiendo perdurado el régimen monárquico durante buena parte del siglo XIX.

Sin embargo, aquellos principios del constitucionalismo moderno que de ella derivaron, y que junto con los que aportó la Revolución Norteamericana entre 1810 y 1812 moldearon los procesos constituyentes de Venezuela y de España, en resumen, fueron los siguientes ${ }^{75}$ :

En primer lugar, la idea de la existencia de una Constitución como carta política escrita, emanación de la soberanía popular, de carácter rígida, permanente, contentiva de normas de rango superior, inmutable en ciertos aspectos y que no sólo organiza al Estado, es decir, no sólo tiene una parte orgánica, sino que también tiene una parte dogmática, donde se declaran los valores fundamentales de la sociedad y los derechos y garantías de los ciudadanos. Hasta el tiempo de las Revoluciones, esta idea de Constitución no existía, y las Constituciones, a lo sumo, era cartas otorgadas por los Monarcas a sus súbditos. La primera Constitución del mundo moderno, por tanto, después de las que adoptaron las antiguas colonias norteamericanas en 1776 fue la de los Estados Unidos de América de 1787, seguida de la de Francia de 1791. La tercera Constitución moderna, republicana, fue la de Venezuela de 1811; y la cuarta, la de la Monarquía parlamentaria de Cádiz de 1812.

En segundo lugar, de esos dos acontecimientos surgió también la idea política derivada del nuevo papel que a partir de esos momentos históricos se confirió al pueblo, es decir, el papel protagónico del pueblo en la constitucionalización de la organización del Estado. Con esas Revoluciones la Constitución comenzó a ser producto del pueblo, dejando de ser una mera emanación de un Monarca. Por ello, en los Estados Unidos de América, las Asambleas coloniales asumieron la soberanía, y en Francia, la soberanía se trasladó del Monarca al pueblo y a la Nación; y a través de la idea de la soberanía del pueblo, surgieron todas las bases de la democracia y el republicanismo.

Por ello, en España, la Junta Central Gubernativa del Reino estableció un régimen de elecciones para la formación de las Cortes de Cádiz en 1810 las cuales sancionaron la Constitución de 18 de marzo de 1812; y en Venezuela, la Junta Suprema conservadora de los derechos de Fernando VII constituida en 1810, entre los primeros actos constitucionales que adoptó, también estuvo la convocatoria a elecciones de un Congreso General con representantes de las Provincias

75 Véase Allan R. Brewer-Carías, Reflexiones sobre la Revolución Norteamericana (1776), la Revolución Francesa (1789) i la Revolución Hispanoamericana (1810-1830) y sus aportes al Constitucionalismo Moderno, Serie Derecho Administrativo No 2, Universidad Externado de Colombia, Editorial Jurídica Venezolana, Bogotá 2008. 
que conformaban la antigua Capitanía General de Venezuela, cuyos diputados (de siete de las nueve Provincias), en representación del pueblo, sancionaron la Constitución de 21 de diciembre de 1811, luego de haber declarado solemnemente la Independencia el 5 de Julio del mismo año.

En tercer lugar, de esos dos acontecimientos políticos resultó el reconocimiento y declaración formal de la existencia de derechos naturales del hombre y de los ciudadanos, con rango constitucional, y por tanto, que debían ser respetados por el Estado. La libertad se constituyó, con esos derechos como un freno al Estado y a sus poderes, produciéndose, así, el fin del Estado absoluto e irresponsable. En esta forma, a las Declaraciones de Derechos que precedieron a las Constituciones de las Colonias norteamericanas al independizarse en 1776, siguieron la Declaración de Derechos del Hombre y del Ciudadano de Francia de 1789, y las Enmiendas a la Constitución de los Estados Unidos del mismo año.

La tercera de las declaraciones de derechos fundamentales en la historia del constitucionalismo moderno, fue la Declaración de Derechos del Pueblo adoptada el $1^{\circ}$ de julio de 1811 por la sección de Caracas del Congreso General de Venezuela, texto que meses después se recogió ampliado, en el Capítulo VII de la Constitución de diciembre de 1811.

En cuarto lugar, además, dentro de la misma línea de limitación al Poder Público para garantizar la libertad de los ciudadanos, las Revoluciones francesa y americana aportaron al constitucionalismo la idea fundamental de la separación de poderes. Esta se formuló, en primer lugar, en la Revolución americana, razón por la cual la estructura constitucional de los Estados Unidos se montó, en 1787 sobre la base de la separación orgánica de poderes. El principio, por supuesto, se recogió aún con mayor fuerza en el sistema constitucional que resultó del proceso revolucionario francés, donde se le agregaron como elementos adicionales, el principio de la supremacía del Legislador resultado de la consideración de la ley como expresión de voluntad general; y el de la prohibición a los jueces de interferir en cualquier forma en el ejercicio de las funciones legislativas $\mathrm{y}$ administrativas.

La Constitución venezolana de diciembre de 1811, en esta forma, fue el tercer texto constitucional del mundo moderno, en establecer expresa y precisamente el principio de la separación de poderes, aun cuando más dentro de la línea del balance norteamericano que de la concepción extrema francesa; siendo la Constitución de Cádiz de 1812, la cuarta Constitución que adoptó el principio de separación de poderes, siguiendo más el esquema francés de la Monarquía parlamentaria.

En quinto lugar, de esos dos acontecimientos políticos puede decirse que resultaron los sistemas de gobierno que han dominado en el mundo moderno: el 
presidencialismo, producto de la Revolución americana; y el parlamentarismo, como sistema de gobierno que dominó en Europa después de la Revolución francesa, aplicado en las Monarquías parlamentarias.

El presidencialismo se instaló en Venezuela a partir de 1811, inicialmente como un ejecutivo triunviral, y luego unipersonal a partir de 1819; y el parlamentarismo se instauró en España en 1812.

En sexto lugar, las Revoluciones americana y francesa trastocaron la idea misma de la función de impartir justicia, la cual dejaría de ser administrada por el Monarca y comenzaría a ser impartida en nombre de la Nación por funcionarios independientes. Además, con motivo de los aportes de la Revolución americana, los jueces asumieron la función fundamental en el constitucionalismo moderno, de controlar la constitucionalidad de las leyes; es decir, la idea de que la Constitución, como norma suprema, tenía que tener algún control, como garantía de su supremacía, y ese control se atribuyó al Poder Judicial. De allí, incluso, el papel político que en los Estados Unidos de Norteamérica, adquirió la Corte Suprema de Justicia. En Francia, sin embargo, dada la desconfianza revolucionaria respecto de los jueces, frente a la separación absoluta de poderes, sólo sería cien años después que se originaría la consolidación de la justicia administrativa, que aún cuando separada del Poder Judicial, controlaría a la Administración; y sería doscientos años después que se establecería un control de constitucionalidad de las leyes a cargo del Consejo Constitucional, creado también fuera del Poder Judicial. Tanto en la Constitución de Venezuela de 1811 como en la Constitución de Cádiz de 1812 se reguló un Poder Judicial autónomo e independiente, habiéndose desarrollado en Venezuela a partir de 1858 un control judicial de la constitucionalidad de las leyes que sólo se instauró en España, efectivamente, a partir de 1978.

En séptimo lugar, de esos dos acontecimientos revolucionarios surgió una nueva organización territorial del Estado, antes desconocida. En efecto, frente a las Monarquías absolutas organizadas conforme al principio del centralismo político y a la falta de uniformismo político y administrativo, esas Revoluciones dieron origen a nuevas formas de organización territorial del Estado, antes desconocidas, que originaron, por una parte, el federalismo, particularmente derivado de la Revolución americana con sus bases esenciales de gobierno local, y por la otra, el municipalismo, originado particularmente como consecuencia de la Revolución francesa.

Venezuela, así, fue el primer país del mundo, 1811, en seguir el esquema norteamericano y adoptar la forma federal en la organización del Estado, sobre la base de la división provincial colonial; y a la vez, fue el primer país del mundo, en 1812, en haber adoptado la organización territorial municipal que legó la Re- 
volución francesa. En España, la división provincial siguió en parte la influencia de la división territorial departamental de la post Revolución francesa; y se adoptaron los principios del municipalismo que también derivaron de la Revolución francesa.

Estos siete principios o aportes que resultan de la Revolución americana y de la Revolución francesa significaron, por supuesto, un cambio radical en el constitucionalismo, producto de una transición que no fue lenta sino violenta, aún cuando desarrollada en circunstancias y situaciones distintas. De allí que, por supuesto, la contribución de la Revolución americana y de la Revolución francesa al derecho constitucional, aún en estas siete ideas comunes, hayan tenido raíces diferentes: en los Estados Unidos de Norte América se trataba de construir un Estado nuevo sobre la base de lo que eran antiguas Colonias inglesas, situadas muy lejos de la Metrópoli y de su Parlamento soberano, y que durante más de un siglo se habían desarrollado independientes entre sí, por sus propios medios y gozando de cierta autonomía. En el caso de Francia, en cambio, no se trataba de construir un nuevo Estado, sino dentro del mismo Estado unitario y centralizado, sustituir un sistema político constitucional monárquico, propio de una Monarquía absoluta, por un régimen totalmente distinto, de carácter constitucional y parlamentario, e incluso luego, republicano. Puede decirse que, mutatis mutandi, en Venezuela ocurrió un fenómeno político similar al de Norteamérica; y en España ocurrió también un fenómeno político similar al de Francia.

\section{ALGUNAS SECUELAS CONSTITUCIONALES DEL DESENCUENTRO}

Seis años después de la restauración de la Monarquía y de la anulación de la Constitución de Cádiz, es decir, a partir de 1820, puede decirse que fue cuando su texto efectivamente comenzaría a tener repercusión en el constitucionalismo moderno. Ello ocurrió como consecuencia de una Revolución de origen militar, y que esa ocasión impuso al rey Fernando VII el juramento de Constitución de Cádiz, la cual entonces volvió a entrar en vigencia, aún cuando por otro corto período de tres años y medio, desde el 10 de marzo de 1820 al primero de octubre de $1823^{76}$.

En efecto, el 1 de enero de 1820 estalló en el pueblo de Cabezas de San Juan, una rebelión militar del cuerpo de expedicionarios que se había conformado y

76 Véase José F. Merino Merchán, Regímenes históricos españoles, Tecnos, Madrid 1988, pp. 60 y 61. 
que debía partir para América para sofocar las rebeliones que ya para esa fecha se habían generalizado en todo el Continente. La voz de la Revolución se expresó con el pronunciamiento de coronel Rafael del Riego, quien, como se ha dicho, consideró «más importante proclamar la Constitución de 1812 que conservar el imperio español» ${ }^{77}$. Para ese momento en Europa, la Constitución de Cádiz era el símbolo de las ideas liberales, más que las que habían derivado de la Revolución Francesa cuyas secuelas habían sumido a toda Europa en unas guerras sucesivas de varias décadas.

Por tanto, entre embarcarse para América para luchar contra un proceso independentista ya bastante generalizado donde las nuevas naciones con sus ejércitos ya habían derrotado a las fuerzas españolas, tal y como por ejemplo, había ocurrido en Venezuela y Nueva Granada respecto de la expedición de Morillo de 1815; y realizar una sublevación militar en la propia España, el Ejercito, con la connivencia de sociedades secretas como la masonería, optó por lo segundo ${ }^{78}$ e hizo la Revolución, imponiendo al Rey la Constitución de 1812, quien la juró el 2 de marzo de 1820 .

En este nuevo período de vigencia, a partir de 1820, fue entonces que la influencia de la Constitución se manifestó incluso en América, en algunas provisiones de los textos Constitucionales de los países en los cuales, para esa fecha, aún no se había proclamado la independencia, que eran la mayoría ${ }^{79}$.

Sin embargo, la mayor repercusión de la Constitución española ocurrió en Europa, donde puede decirse que su influencia derivó, más que del texto estricto de las previsiones contenidas en la Constitución, del hecho de que en su nombre se había realizado una revolución que había impuso por la fuerza la Constitución al Monarca en 1820. Así, la decisión del Rey de jurar la Constitución como consecuencia de esa Revolución, fue realmente lo que consolidó al movimiento como la primera Revolución liberal europea. La consecuencia de ello fue, entonces, que los movimientos revolucionarios que en esas mismas fechas se iniciaron tanto en Portugal como en Nápoles y en el Piamonte italiano, vieron en la Revolución española el ejemplo a seguir, imponiendo también a los Monarcas su producto, que había sido, precisamente, la Constitución de Cádiz.

77 Véase Juan Ferrando Badía, «Proyección exterior de la Constitución de Cádiz» en M. Artola (ed), Las Cortes de Cádiz, Ayer, 1-1991, Marcial Pons, Madrid 1991, p. 207.

78 Véase F. Suárez, La crisis política del Antiguo Régimen en España (1800-1840), Madrid, 1950, p. 38. Citado por Juan Ferrando Badía, Idem, p. 177.

79 Véase por ejemplo, Manuel Ferrer Muñoz, La Constitución de Cádiz y su aplicación en la Nueva España, UNAM, México 1993. 
En los Estados de Venezuela, en cambio, el desencuentro continuó, y aún antes de haber concluido las guerras de independencia con la Batalla de Carabobo de 1821, y antes de que se hubiese vuelto a poner en vigencia la Constitución de Cádiz en 1820, luego de efectuadas las elecciones para la conformación del Congreso de Venezuela ${ }^{80}$, el 15 de agosto de 1819 se sancionó en Angostura, capital de la provincia de Guayana, la segunda Constitución política de Venezuela ${ }^{81}$, la cual por supuesto, tuvo como antecedente inmediato el texto de la Constitución Federal de los Estados de Venezuela de 1811, de la cual tomó muchas disposiciones, entre ellas, la declaración de derechos, los principios democráticos representativos y la separación de poderes. Esta Constitución tuvo, además, la influencia directa de las ideas de Simón Bolívar, para entonces jefe supremo de la República, quien las había expresado tanto en el Proyecto de texto constitucional que elaboró para el Congreso, como en su Discurso de presentación del mis$\mathrm{mo}^{82}$; los cuales además, seguían la línea de pensamiento que había delineado en el Manifiesto de Cartagena (1812) y en la Carta de Jamaica (1815) ${ }^{83}$. La Constitución de 1819, sin embargo, tuvo una importante disidencia respecto del texto de la Constitución de 1811, al establecer, conforme a la orientación de Bolívar, un Estado unitario en contraste con la forma federal inicial.

Esta organización constitucional del Estado de Venezuela en la Constitución de Angostura, como la guerra de independencia no había concluido, y la mira del Libertador apuntaba además, hacia la Nueva Granada, a finales el 17 de diciembre de ese año 1819, el propio Congreso de venezuela, en virtud de que a su autoridad habían querido sujetarse los pueblos de la nueva Granada recientemente liberados, sancionó la Ley Fundamental de la República de Colombia en $1819^{84}$, reuniendo «las Repúblicas de Venezuela y la Nueva Granada»... en una

${ }^{80}$ Véase el texto del Reglamento para elecciones de representantes al Congreso de Venezuela de 17-10-1818 aprobado por el Consejo de Estado constituido por el Libertador como jefe Supremo, en Allan R. Brewer-Carías, Las Constituciones de Venezuela, cit., Tomo I, pp. 603-611. El Consejo de Estado lo había creado el Libertador el 5 de noviembre de 1817. Véase en Idem, p. 599.

${ }^{81}$ Idem, Tomo I, p. 599.

${ }^{82}$ Véase los textos en El Libertador y la Constitución de Angostura, (ed. Pedro Grases), Publicaciones del Congreso de la República, Caracas, 1969.

${ }^{83}$ El Manifiesto de Cartagena (1812) y la Carta de Jamaica (1815) pueden consultarse, entre otros, en Simón Bolívar, Escritos Fundamentales, Caracas, 1982 y en Itinerario Documental de Simón Bolivar. Escritos selectos, Ediciones de la Presidencia de la República, Caracas 1970, pp. 30 y ss. y 115 y ss. Véase además, Simón Bolívar, Carta de Jamaica, Ediciones del Ministerio de Educación, Caracas 1965 y Ediciones de la Presidencia de la República, Caracas 1972.

${ }^{84}$ Véase el texto en Allan R. Brewer-Carías, Las Constituciones de Venezuela, cit., Tomo I, pp. 645-646; y en Pedro Grases (ed), Actas del Congreso de Angostura, cit., pp. 356 y ss. 
sola bajo el título glorioso de república de Colombia» (art. 1), cuyo territorio comprendía al antiguo reino de Quito (art. 2) ${ }^{85}$. Por ello, a comienzos de 1820 Bolívar regresó a la Nueva Granada y luego de volver a Venezuela en marzo de ese año —cuando los rebeles militares en España imponían a Fernando VII la Constitución de Cádiz_- en la continuación de la guerra a la cual los militares españoles se habían negado participar, derrotando los ejércitos españoles los días 25 y 26 de noviembre de 1820, Bolívar y Morillo suscribieron un Armisticio y un Tratado de Regularización de la Guerra con Pablo Morillo, entrevistándose en Santa Ana, el 27 de noviembre de 1820. Todo esto, como se dijo, ocurría en las provincias americanas mientras en España se producía y se comenzaba a consolidar la revolución de Riego. Luego del armisticio, Morillo encargó del ejército español a Miguel de la Torre y se embarcó para España, pero al poco tiempo, el Armisticio se rompió por el pronunciamiento del gobierno de la Provincia de Maracaibo, que había permanecido leal a la Monarquía, a favor de una República democrática, incorporándose a Colombia. Finalmente el 24 de junio de 1821 se libró la Batalla de Carabobo, y con ello se selló definitivamente la independencia de Venezuela.

La independencia, constitucionalmente se materializó en la Constitución de la República de Colombia sancionada por el Congreso General de Colombia reunido en la Villa del Rosario de Cúcuta el 30 de agosto de $1821^{86}$, una vez que el mismo Congreso había sancionado la Ley Fundamental de la Unión de los Pueblos de Colombia del 15 de agosto de $1821^{87}$, estuvo signada igualmente por el centralismo de Estado que continuó y se acentuó, al integrarse en un solo Estado todas las provincias de Cundinamarca, Venezuela y Ecuador.

Esa República, obra de Bolívar, sin embargo, desapareció tres meses antes de su muerte, con el desmembramiento de la llamada Gran Colombia y por lo que respecta a Venezuela, con la sanción de la Constitución del 24 de septiembre de 1830 mediante la cual se restableció la República de Venezuela ${ }^{88}$. Su texto fue uno de los que más influencia tuvo en el proceso constitucional venezolano, dado los largos años de vigencia de los que gozó hasta 1857. Fue un texto que siguió la misma línea constitucional que se había iniciado en Venezuela con la Constitución Federal de 1811, de cuyo texto recibió la influencia fundamental, así

85 Véase la Ley Fundamental de la República de Colombia de 17-12-1819 en Allan R. Brewer-Carías, Las Constituciones de Venezuela, cit., Tomo I, pp. 643-644.

86 Idem, Tomo I, pp. 647-665.

87 Que se sancionó ratificando la Ley Fundamental de la República de Colombia de 17-121819. Véase en Idem, Tomo I, pp. 645-646.

88 Idem, Tomo I, pp. 707 ss. 
como de las Constituciones de 1819 y 1821, aún cuando mitigando el centralismo que Bolívar le había propugnada en ellas.

Así, de la divergencia política inicial entre Caracas y Cádiz durante los cruciales años de 1810 a 1812, sin duda derivaron procesos constituyentes propios y distintos que se desarrollaron en paralelo en ambas partes del Atlántico, pero que, con todas sus vicisitudes políticas, encontraron puntos de convergencia por el hecho de haber recibido, en ambas partes del Atlántico, la influencia de los mismos principios del constitucionalismo moderno provenientes de las Revoluciones Francesa y Norteamericana del siglo XVIII.

New York, junio 2011

Title:

CHRONICLE OF A MIX-UP: The PROVINCES OF VENEZUELA AND CORTES OF CADIZ (1810-1812)

\section{Summary:}

1. A point of convergence in the origin of the mix-up: the crisis of the Old spanish Regime. 2. The representative routes democratic that lead to the mix-up. 3. The consolidation of the mix-up: the war decreed by the regency and continued by Cortes of Cadiz, against the provinces of Venezuela. 4. The constitutional convergence between Caracas (1811) and Cadiz (18120, in spite of the mix-up, by the reception of such principles of the modern constitutionalism. 5. Some constitutional sequels of the mix-up.

\section{Resumen:}

La declaración de independencia de las Provincias de Venezuela respecto de la Monarquía hispánica abrió el proceso constituyente que culminó con la promulgación de la Constitución Federal para los Estados de Venezuela (1811) y la Ley Fundamental de la República de Colombia (1821). La metrópoli fue refractaria a la emancipación política de estos territorios y trató manu militari de reconducirla a la unidad de la monarquía, lo que desató un prolongado período de enfrentamientos bélicos durante la segunda década del siglo XIX hasta su conclusión en la Batalla de Carabobo de 1821. Sin embargo, esta hostilidad no impidió la convergencia de los procesos constituyentes desarrollados a ambos del Atlántico ya que ambos, el de Cádiz y el de Venezuela, estuvieron iluminados por los principios liberales de la Revolución americana y francesa. 


\begin{abstract}
:
The declaration of independence of the Provinces of Venezuela respect to the Hispanic Monarchy opened the constituent process that culminated with the promulgation of the Federal Constitution for the States of Venezuela (1811) and the Fundamental Law of the Republic of Colombia (1821). The metropolis was refractory to the political emancipation of these territories and tried manu militari to lead back it to the unit of the monarchy, which untied a prolonged period of warlike confrontations during the second decade of century XIX until its conclusion in Battle de Carabobo of 1821. Nevertheless, this hostility did not prevent the convergence of the developed constituent processes to both of the Atlantic since both, the one of Cadiz and the one of Venezuela, were illuminated by the liberal principles of the American and French Revolution.
\end{abstract}

\title{
Palabras clave:
}

Independencia, constitucionalismo venezolano, liberalismo y Manifiesto de 1811.

\section{Key words:}

Independence, venezuelan constitutionalism, liberalism and Manifesto of 1811. 